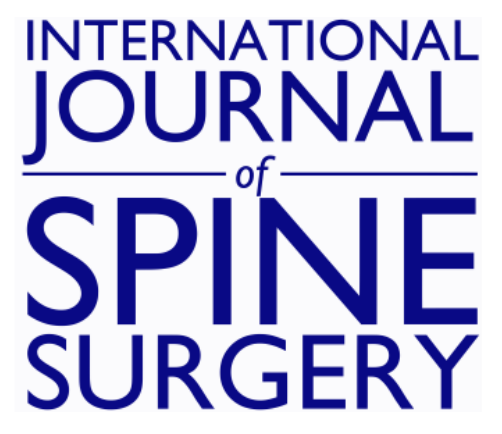

\title{
Does Capacitively Coupled Electric Fields Stimulation Improve Clinical Outcomes After Instrumented Spinal Fusion? A Multicentered Randomized, Prospective, Double-Blind, Placebo-Controlled Trial
}

\author{
LEO MASSARI, GIOVANNI BARBANTI BRODANO, STEFANIA SETTI, GAETANO \\ CARUSO, ENRICO GALLAZZI, SIMONA SALATI and MARCO BRAYDA-BRUNO
}

Int J Spine Surg 2020, 14 (6) 936-943

doi: https://doi.org/10.14444/7142

http://ijssurgery.com/content/14/6/936

This information is current as of April 25, 2023.

Email Alerts Receive free email-alerts when new articles cite this article. Sign up at: http://ijssurgery.com/alerts 


\title{
Does Capacitively Coupled Electric Fields Stimulation Improve Clinical Outcomes After Instrumented Spinal Fusion? A Multicentered Randomized, Prospective, Double-Blind, Placebo-Controlled Trial
}

\author{
LEO MASSARI, MD,${ }^{1}$ GIOVANNI BARBANTI BRODANO, $\mathrm{MD},{ }^{2}$ STEFANIA SETTI, MSC, ${ }^{3}$ GAETANO \\ CARUSO, MD, ${ }^{1}$ ENRICO GALLAZZI, MD ${ }^{4}$ SIMONA SALATI, PHD,${ }^{3}$ MARCO BRAYDA-BRUNO, MD ${ }^{4}$ \\ ${ }^{I}$ Department of Biomedical and Specialty Surgical Sciences, Azienda Ospedaliero-Universitaria di Ferrara, Arcispedale Sant'Anna, University of Ferrara, Ferrara, \\ Italy, ${ }^{2}$ Department of Oncological and Degenerative Spine Surgery, IRCCS Istituto Ortopedico Rizzoli, Bologna, Italy, IGEA SpA, Clinical Biophysics, Carpi, \\ Italy, ${ }^{4}$ Spine Surgery III and Scoliosis Department, IRCCS Istituto Ortopedico Galeazzi, Milano, Italy
}

\begin{abstract}
Background: Lumbar spinal fusion (LSF) is used to treat lumbar degenerative disorders. Methods to improve the functional recovery of patients undergoing LSF is one of the main goals in daily clinical practice. The objective of this study is to assess whether biophysical stimulation with capacitively coupled electric fields (CCEF) can be used as adjuvant therapy to enhance clinical outcome in LSF-treated patients.

Methods: Forty-two patients undergoing LSF were assessed and randomly allocated to either the active or to the placebo group. Follow-up visits were performed at 1, 3, 6, and 12 months after surgery; long-term follow-up was performed at year 10. Visual analogue scale (VAS), the Oswestry Disability Index (ODI), and the 36-item Short Form Health Survey (SF-36) questionnaire were recorded.

Results: This study demonstrates a significant improvement in CCEF-treated patients at 6 and 12 months' followup for SF-36, and at 12 months' follow-up for ODI values. Based on SF-36 and ODI scores, we reported a significantly higher percentage of successful treatments at 12 months in the active compared with the placebo group. Moreover, in a subset of patients at 10 years' follow-up, a significant difference was reported in VAS and ODI scores between groups.

Conclusions: The results demonstrate that 3 months of CCEF treatment immediately after surgery is effective in reducing ODI and improving SF-36 score, and that these benefits can be maintained up to 12 months. In a subset of patients, these positive outcomes are retained up to 10 years.
\end{abstract}

Level of Evidence: I.

Clinical Relevance: This study suggests that CCEF stimulation can be used as an adjunct to LSF for spine diseases, for increasing overall quality of life and improving patients' functional recovery. CCEF is safe and well tolerated, compatible with activities of daily living.

Lumbar Spine

Keywords: spinal fusion, capacitively coupled electric fields, quality of life, chronic back pain, randomized prospective placebo-controlled trial, level I

\section{INTRODUCTION}

Lumbar spinal fusion (LSF) is the end stage treatment for spinal pain caused by a wide range of degenerative conditions, such as spinal stenosis, instability, degenerative spondylolisthesis, and degenerative disc disease. The number of LSFs performed worldwide has steadily increased in the last years. However, the outcomes are not always satisfactory, because of conflicting results and recommendations in the literature regarding the postsurgery management to improve clinical out- comes of patients. Mannion et $\mathrm{al}^{1}$ described no statistically significant or clinically relevant differences in patients with chronic low back pain treated with either LSF or rehabilitation over 11 years' follow-up. Moreover, 2 systematic reviews failed to show superiority of surgical treatment compared with conservative treatment in discogenic low back pain and lumbar degenerative spondylosis. ${ }^{2,3}$

Given these premises, one of the main goals of current research on this field is finding methods to improve the clinical outcomes of patients undergo- 
ing LSF, in particular concerning low back pain and disability.

Physical stimuli have been extensively reported in literature to improve fracture's healing, as well as to enhance fusion rates after spinal surgery. ${ }^{4}$ Clinical trials demonstrated therapeutic efficacy of biophysical stimulation with the use of Pulsed ElectroMagnetic Field (PEMF) and, in most recent years, with Capacitively Coupled Electric Field (CCEF) for treatment of degenerative and traumatic lesions, in terms of pain relief and functional recovery. ${ }^{4}$

In preclinical studies, CCEF demonstrated positive effects on both bone formation and inflammatory response. ${ }^{5}$ CCEF has been shown to increase cytosolic $\mathrm{Ca}^{2+}$ levels and upregulate the expression of osteogenic genes, such as transforming growth factor- $\beta$ genes, fibroblast growth factor- 2 , osteocalcin, and alkaline phosphatase. ${ }^{6}$ In castrationinduced osteoporosis models, CCEF promotes bone fracture healing and nonunion repair. ${ }^{7}$ Clinical studies showed that CCEF improved fusion rates and reduced chronic back pain after lumbar surgery. ${ }^{8}$ Moreover, CCEF reduced nonsteroidal anti-inflammatory drug (NSAID) use and improved quality of life (QoL) after vertebral osteoporotic and compression fractures. ${ }^{9,10}$

These evidences suggest that CCEF could have a beneficial role following LSF. We designed a multicentered, randomized, prospective, double-blind, placebo-controlled trial with the primary aim of evaluating whether CCEF reduces disability index (Oswestry Disability Index, ODI) and improves QoL following instrumented spinal fusion for degenerative and traumatic disorders.

\section{MATERIALS AND METHODS}

\section{Study Group}

This multicenter, randomized, prospective, double-blind, placebo-controlled trial was approved by ethics committee of each of the institutions involved. Written informed consent was obtained by all patients at the enrollment visit.

Inclusion criteria were as follows: spine disorders with the need for an instrumented spinal fusion up to 2 intervertebral disc spaces. Patients with primitive or secondary spinal tumors, systemic disease such as rheumatoid arthritis or other inflammatory arthropathies, chronic renal failure stage 2 or worse, type 1 or type 2 diabetes mellitus in insulin treatment, and hypo or hyperthyroidism were excluded from this study, as well as patients with previous vertebral arthrodesis at the same level.

\section{Surgical Treatment}

The spinal fusion techniques used were as follows:

- Posterior/posterolateral fusion with pedicle screws and rods.

- Posterior lumbar interbody fusion (PLIF) with cages, screws, and rods.

- Anterior lumbar interbody fusion (ALIF) with anterior interbody cages, screws, and plates or rods.

\section{CCEF Treatment Protocol}

Patients who met the inclusion criteria were randomly allocated to either active CCEF stimulation or to the placebo group. Patients were randomly assigned to the active or placebo group using a web-based randomization program built on the randomization criteria: sex (male/female), age (18-60, >60 years), spinal fusion techniques (PLIF/ posterolateral fusion/ALIF), and smoking status (yes/no). For each patient, data were collected and inserted in a clinical report form.

The device used was OsteoSpine (IGEA SpA, Carpi, Italy). This medical device weights $140 \mathrm{~g}$, and provides a density current of $25 \mu \mathrm{A} / \mathrm{cm}^{2}$ in the region of interest. The signal consists of $12.5 \mathrm{~Hz}$ burst with a duty cycle of $50 \%$. The active part of the burst is a sinusoidal wave of $60 \mathrm{kHz}$ with an amplitude adjusted by a microprocessor according to the impedance of the body interposed between the electrodes. The body region covered by CCEF equals the length of the 2 electrodes pad and goes as deep as the fusion mass and the vertebral bodies (Figure 1). This setting allows the stimulation of 2 intervertebral disc spaces. The pad is made of highly conductive material covered with adhesive gel. Previous studies have shown a good skin tolerability of the device. ${ }^{9-11}$ The device comes with a build-in software that records the stimulation times.

Patients were taught and asked to place the pad paraspinally at the level of the surgical intervention, starting the stimulation 7 days after surgery, for 9 hours per day for 90 days. According to the allocation group, the patient received 1 of 2 devices by an independent research assistant, who will not be involved in patient care or assessment. Physi- 


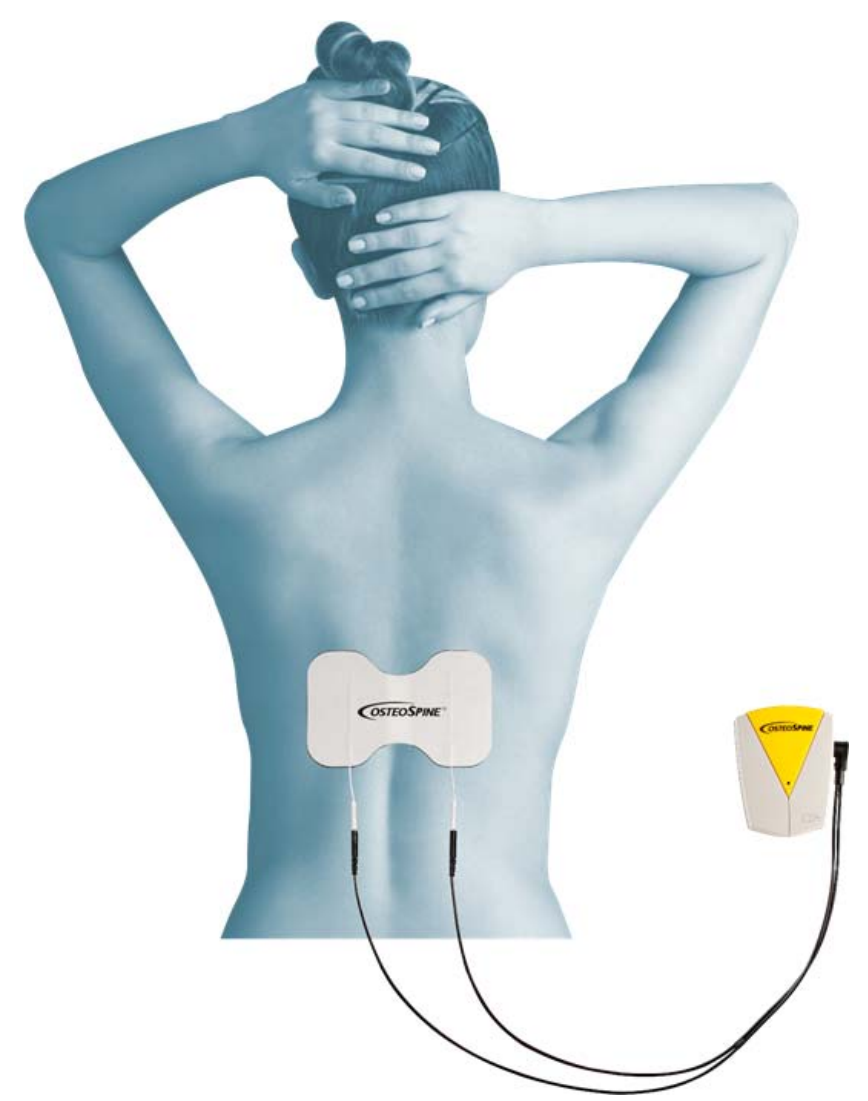

Figure 1. The OsteoSpine device (IGEA SpA). Correct positioning of the electrodes pad.

cians, as well as medical assessors, were blinded to the allocation of patients in the study groups. The study group received a completely functional device that provided the therapeutic signal described above; the placebo group received a sham device, externally identical to the active one, that provided a $0.1 \mathrm{~V}$ peak-to-peak sine wave, the minimum amount of current that allowed the generator to record skin contact and thus monitor the effective time of utilization.

\section{Data Collection and Clinical Assessment}

Clinical data were collected at the enrollment visit. Physical examination was performed. Pain was recorded using the Visual Analogue Scale (VAS). ${ }^{12}$ QoL was recorded using the ODI and the 36-item Short Form Health Survey (SF-36) questionnaire. ${ }^{12,13}$ Type of surgery and levels of arthrodesis were recorded. Follow-up visits were performed at 1, 3 (end of CCEF treatment), 6, and 12 months after surgery. A subset of patients was re-evaluated at 10 years; VAS, ODI, and SF-36 values were recorded.

\section{Statistical Methods}

Power analysis is as follows: based on our clinical experience, a difference of 6 points in ODI, with a standard deviation of 6 can be considered a relevant difference between groups at the end of the followup period. Group sample sizes of 17 each achieve an $80 \%$ power to reject the null hypothesis of equal means when the population mean difference is 6.0 with a standard deviation for both groups of 6.0 and with a significance level $(\alpha)$ of 0.050 using a 2 -sided 2-sample equal-variance $t$ test.

For continuous variable, means and standard deviations were obtained. In order to evaluate whether the surgical intervention was successful in improving the QoL (from now on referred to as successful treatment), we considered a 9 points difference of the ODI subjective-evaluation score as clinically relevant. Mannion et al ${ }^{14}$ defined "minimum detectable change" ( $\mathrm{MDC}_{95 \%}$ ) for the ODI of approximately 9 points as the minimum change in an individual's score required to be considered "real change" (with 95\% confidence) over and above measurement error. Under this assumption, we calculated the percentage of patients with an increase greater of 9 points in ODI during followup. In the same way, we considered an increase of 10 points in SF-36 Health Survey with respect to baseline as a minimal expected increase in a single patient experiencing a benefit from the therapy. ${ }^{15,16}$ Percentage of successful treatment was obtained for each group at 6 and 12 months, and compared using the Fisher exact test.

\section{RESULTS}

Forty-two of the 50 eligible patients (17 allocated in the active group and 25 allocated in the placebo group) completed the follow-up; 8 patients allocated in the active group were excluded from the study (Figure 2).

Demographics, clinical characteristics at the baseline, and overall time of therapy of the 2 groups are reported in Table 1 . The 2 groups were comparable for baseline characteristics. No significant differences were found between the 2 groups regarding the hours of treatment $(604 \pm 354$ in the active group versus $635 \pm 312$ in the placebo group). Table 2 shows no significant difference between the 2 groups for the disease and treatment parameters analyzed. 


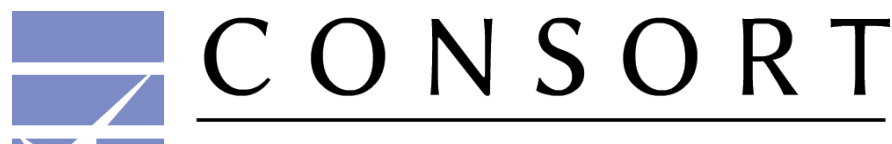

TRANSPARENT REPORTING of TRIALS

\section{CONSORT 2010 Flow Diagram}

\section{Enrollment}

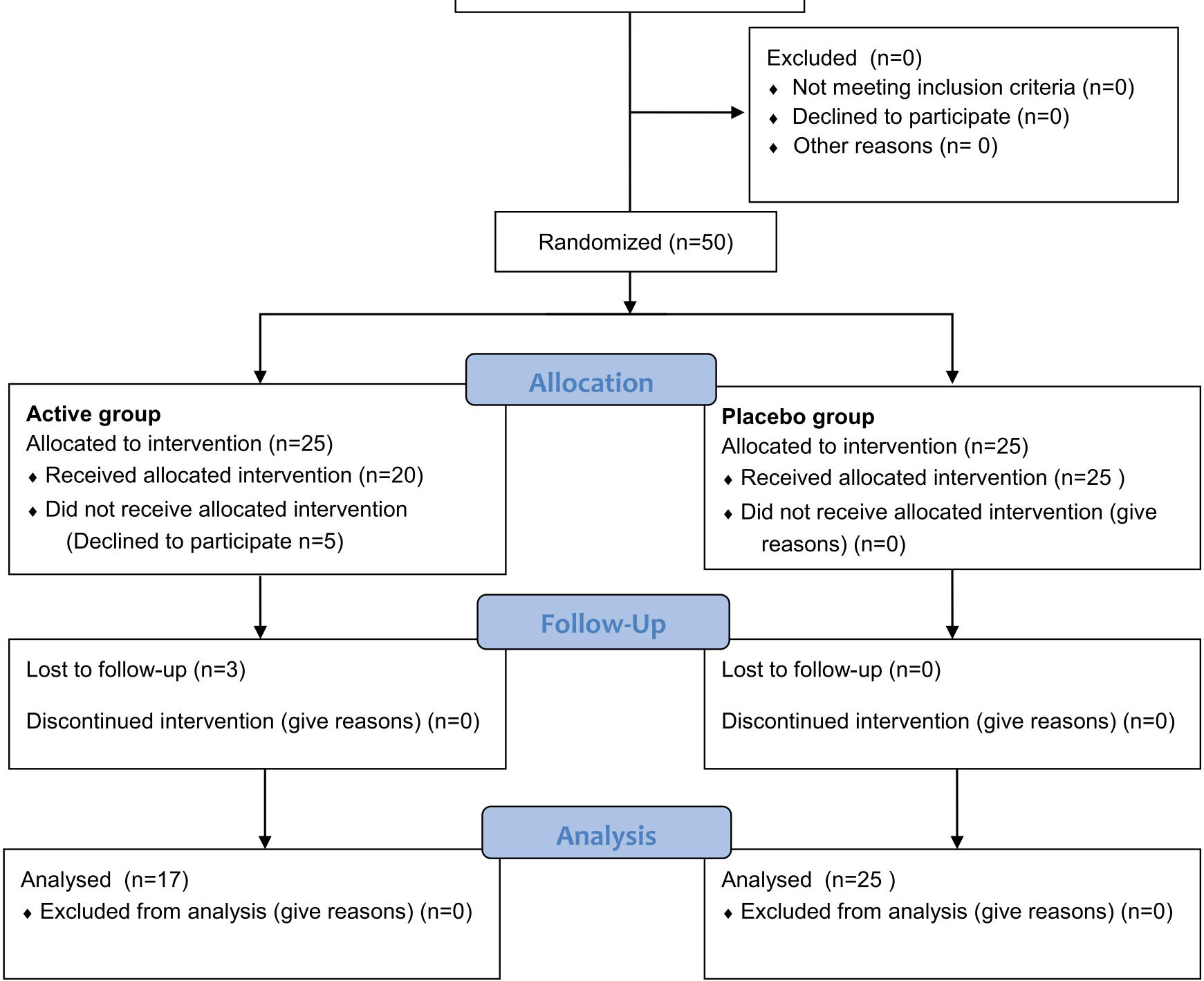

Figure 2. Consolidated Standards of Reporting Trials (CONSORT) flow chart for patient enrolment.

No adverse events related to the use of the device were recorded. No intra- or perioperative adverse events occurred, and no revision surgeries were performed by the end of follow-up. No statistically significant difference in VAS was recorder between the 2 groups (data not shown).

Mean ODI values for each group and mean variation compared with baseline values were 
Table 1. Baseline characteristics of the 2 study groups.

\begin{tabular}{lccc}
\hline Characteristics & Active Group $(\mathbf{n}=\mathbf{1 7}[\mathbf{1 0} \mathbf{~ F / 7 ~ M ] )}$ & Placebo Group $(\mathbf{n}=\mathbf{2 5}[\mathbf{1 2}$ F/13 M $])$ & $\boldsymbol{P}$ Value \\
\hline Age, mean \pm SD, y & $57 \pm 12$ & $56 \pm 15$ & .72 \\
Weight, mean \pm SD, kg & $77 \pm 16$ & $78 \pm 17$ & .76 \\
Height, mean \pm SD, cm & $164 \pm 8$ & $168 \pm 13$ & .57 \\
ODI, mean \pm SD & $56 \pm 20$ & $50 \pm 24$ & .56 \\
SF-36, mean \pm SD & $16 \pm 15$ & $20 \pm 16$ & .71 \\
Smokers (n)/nonsmokers (n) & $2 / 15$ & $6 / 19$ & .55 \\
\hline
\end{tabular}

Abbreviations: F, females; M, males; ODI, Oswestry Disability Index; SF-36, 36-item Short Form Health Survey.

calculated for each time point (Figure 3). A significant improvement in ODI value was recorded in both groups from the preoperative to the first postoperative evaluation, and this improvement remained constant throughout the follow-ups. Worth of notice, in the study group, at 12 months the ODI value was significantly lower than in the placebo group $(P<.05)$. We observed a significantly higher percentage of successful treatment at 12 months in the study than in the placebo group ( $P$ $<.05$ ) (Table 3).

As far as the SF-36 score is concerned, we recorded an improvement at 3, 6, and 12 months compared with baseline in both groups. SF-36 mean variation compared with baseline values (delta SF36) was calculated for each time point: a significant improvement was recorded in both groups, but at 1 month follow-up, this increase was statistically significant only in the active group $(P<.05)$ (Figure 4, panel A).

If we narrow the analysis to the patients who completed the SF-36 questionnaire at each followup, the score showed an improvement in the active group compared with the placebo group, with

Table 2. Patient diagnosis and surgical procedures.

\begin{tabular}{lccc}
\hline Characteristics & $\begin{array}{c}\text { Active } \\
\text { Group, \% }\end{array}$ & $\begin{array}{c}\text { Placebo } \\
\text { Group, \% }\end{array}$ & $\begin{array}{c}P \\
\text { Value }\end{array}$ \\
\hline Diagnosis & & & .7111 \\
$\quad$ Traumatic vertebral disease & 12 & 17 & \\
DDD and segmental spine instability & 47 & 54 & \\
$\quad$ DDD and spinal stenosis & 41 & 29 & \\
Type of fusion & & & .6007 \\
$\quad$ Posterolateral & 88 & 80 & \\
$\quad$ Circumferential & 12 & 20 & \\
Range of fusion & & & .9392 \\
$\quad$ Single & 41 & 40 & \\
$\quad$ Multiple & 59 & 60 & \\
Region & & & .5013 \\
$\quad$ Lumbar & 65 & 48 & \\
$\quad$ Lumbosacral & 29 & 36 & \\
$\quad$ Thoracolumbar & 6 & 16 & \\
Spinal fusion technique & & & .3247 \\
$\quad$ PLIF & 70.5 & 76 & \\
PLF & 29.5 & 16 & \\
ALIF & 0 & 8 & \\
\end{tabular}

Abbreviations: ALIF, anterior lumbar interbody fusion; DDD, degenerative disc disease; PLF, posterolateral fusion; PLIF, posterior lumbar interbody fusion. differences being statistically significant at 6 and 12 months $(P=.03$ and $P=.04)$ (Figure 4, panel $\mathrm{B})$. We observed a significantly higher percentage of successful treatment at 6 and 12 months in the study group versus the placebo group $(P<.05)$ (Table 4$)$.

A subset of patients (6 in the active group and 10 in the placebo group) was re-evaluated after 10 years from surgery. ODI and VAS scores showed a statistically significant improvement in the active compared with the placebo group (Figure 5).

\section{DISCUSSION}

LSF with or without decompression surgery is frequently used for the treatment of lumbar degenerative disorders despite conflicting result. ${ }^{17}$ The incidence of lumbar fusion surgeries between 1992 and 2003 has increased from $0.3 / 1000$ to 1.1/ 1000 enrollees. $^{18}$ However, the clinical outcome after LSF remains a subject of controversy.

Biophysical stimulation is one of the therapies available to increase the success rate of bone fracture healing. ${ }^{4}$ Two types of biophysical stimulation have been used in the last century for the management of spine diseases: PEMF and CCEF. These techniques have been reported to (i) induce osteoblast proliferation and differentiation, (ii) stimulate the mineralization process and increase

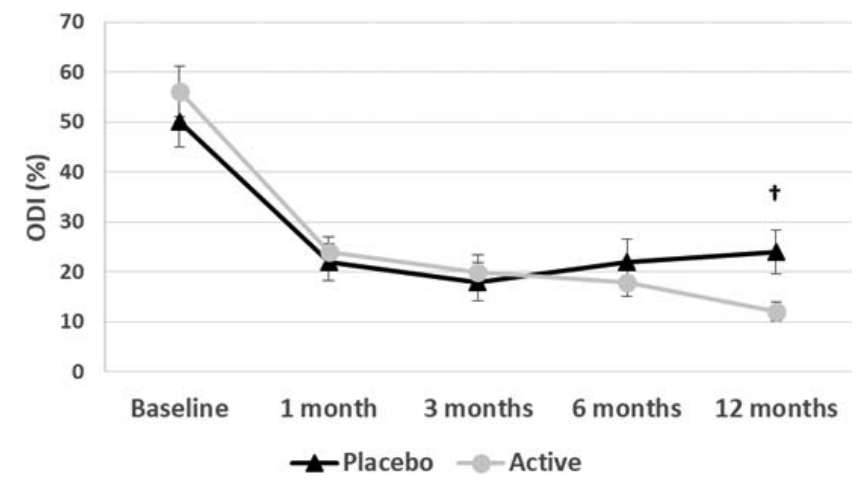

Figure 3. Quality of life measured by the Oswestry Disability Index (ODI). Graph showing mean ODI values, reported as mean \pm SE. $P$ value refers to a comparison between groups at each follow-up visit $(\dagger P<.05)$. 
Table 3. Evaluation of successful treatments based on Oswestry Disability Index (ODI) score. "Successful treatment" was defined as a reduction of at least 9 points in ODI from the preoperative values. Data from patients with completed follow-up only are shown.

\begin{tabular}{cccccccc}
\hline & \multicolumn{2}{c}{ Active Group } & & \multicolumn{2}{c}{ Placebo Group } & & Fisher \\
\cline { 2 - 3 } & $\begin{array}{c}\text { N Success/ } \\
\text { N Total }\end{array}$ & $\begin{array}{c}\text { Success, } \\
\mathbf{\%}\end{array}$ & & $\begin{array}{c}\text { N Success/ } \\
\text { N Total }\end{array}$ & $\begin{array}{c}\text { Success, } \\
\boldsymbol{\%}\end{array}$ & & $\boldsymbol{P}$ Value \\
\hline 12 months & $12 / 13$ & 92 & & $10 / 16$ & 63 & .03 \\
\hline
\end{tabular}

bone healing, and (iii) inhibit osteoclast differentiation and osteolysis. ${ }^{4,19}$

The first report on the clinical efficacy of PEMFs in failed PLIFs comes from Simmons et al. ${ }^{20}$ who showed healed interbody fusion in $77 \%$ of PEMFstimulated patients. These results have been recently confirmed by Risso Neto et al. $^{21}$ : in patients undergoing instrumented lumbar posterolateral arthrodesis, the authors showed that the PEMFstimulated group had a $276 \%$ greater chance of consolidation in the vertebral levels compared with the sham group. Several authors reported similar effects of PEMF stimulation in patients undergoing LSF surgeries. ${ }^{22-24}$ However, Mooney ${ }^{24}$ described a drop off rate of $20 \%$ and inconsistent use of the PEMF device in $35 \%$ of the subjects. These effects have been accounted to the discomfort of the PEMF device. The CCEF device on the contrary has proven much more comfortable, due to its smaller and lighter applicators, thus providing improved patient compliance. By means of CCEF stimulation, Goodwin et al. $^{8}$ reported a fusion success rate of $84 \%$ versus $64.9 \%(P<.01)$ and a clinical success rate of $88.2 \%$ versus $75.5 \%(P<.05)$, in the comparison between active group versus placebo group.

\section{A}

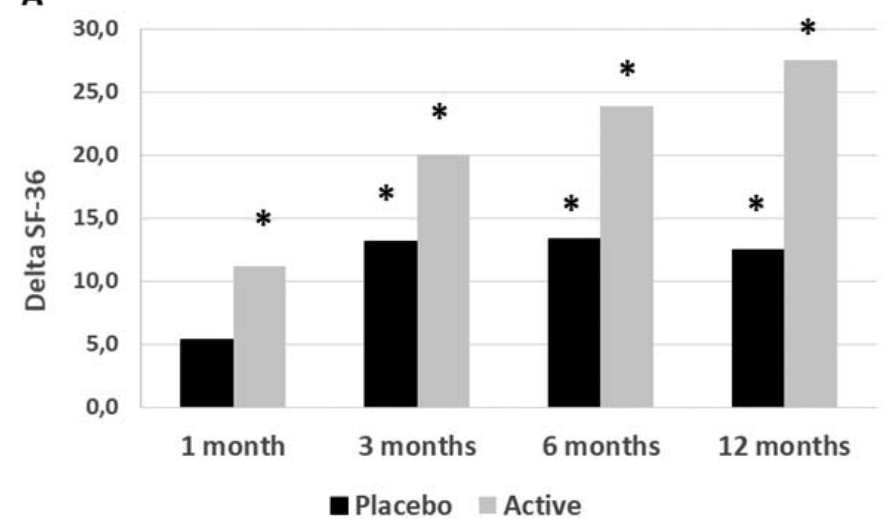

Table 4. Evaluation of successful treatments based on the 36-item Short Form Health Survey (SF-36) score. "Successful treatment" was defined as an increase of at least 10 points in the SF-36 from the preoperative values. Data from patients with completed follow-up only are shown.

\begin{tabular}{|c|c|c|c|c|c|}
\hline & \multicolumn{2}{|c|}{ Active Group } & \multicolumn{2}{|c|}{ Placebo Group } & \multirow{2}{*}{$\begin{array}{l}\text { Fisher } \\
P \text { Value }\end{array}$} \\
\hline & $\begin{array}{l}\text { N Success/ } \\
\text { N Total }\end{array}$ & $\begin{array}{c}\text { Success, } \\
\%\end{array}$ & $\begin{array}{l}\text { N Success/ } \\
\text { N Total }\end{array}$ & $\begin{array}{c}\text { Success, } \\
\%\end{array}$ & \\
\hline $6 \mathrm{mo}$ & $14 / 16$ & 88 & $7 / 15$ & 47 & .007 \\
\hline 12 months & $11 / 14$ & 79 & $7 / 16$ & 44 & .02 \\
\hline
\end{tabular}

Mooney $^{24}$ pointed out that not all the radiographic fusion success led to an improvement of clinical results, and that some clinical success occurred despite radiologic evidence of pseudarthrosis. Dhall et al. ${ }^{25}$ highlighted that achieving a solid arthrodesis following a spinal fusion procedure is generally believed to be an important goal; however, the relationship between successful fusion and clinical outcome has not been fully established. Therefore, pain relief and overall QoL are critical aspects to be assessed when evaluating spinal fusion outcomes.

CCEF have been proven from the literature to be effective on pain control and on reduction of NSAIDs use. Rossini et al. ${ }^{9}$ described a dosedependent effect on pain relief in the CCEF active group. Piazzolla et al. ${ }^{10}$ demonstrated an improvement of clinical symptoms with faster fracture healing and a significant reduction in the area of vertebral bone marrow edema, with pain resolution times reduced by half in CCEF-stimulated patients.

Altogether, these reports suggest that CCEF might have a positive impact on patients undergoing LSF. To assess this hypothesis, we designed a randomized controlled trial with the aim of evalu-

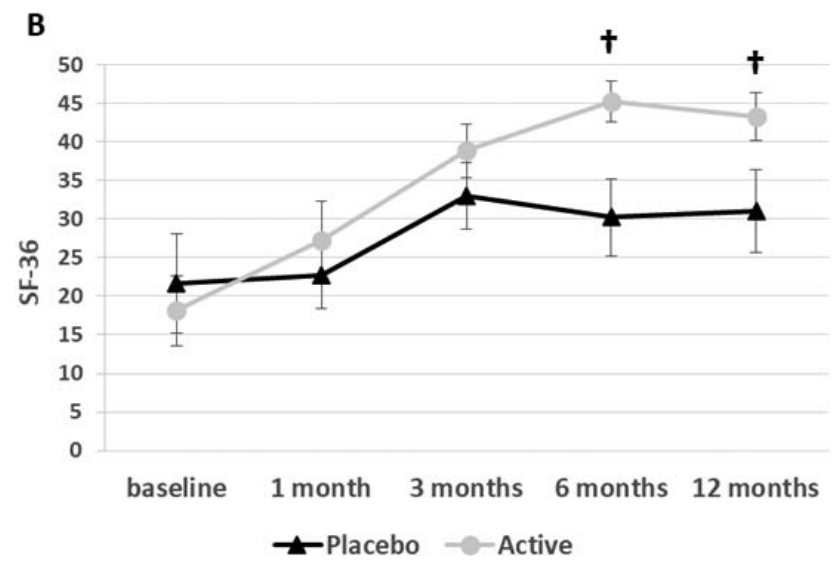

Figure 4. Quality of life measured by the SF-36 Health Survey score. Graph showing mean variation compared with baseline values (A; $P$ values are reported for differences between each follow-up versus baseline $\left.\left[{ }^{\star} P<.05\right]\right)$ and mean SF-36 Health Survey values, reported as mean \pm SE for patients who completed the clinical report form at each follow-up (B; $P$ values refer to a comparison between groups at each follow-up visit [† $P<.05]$ ). 
A

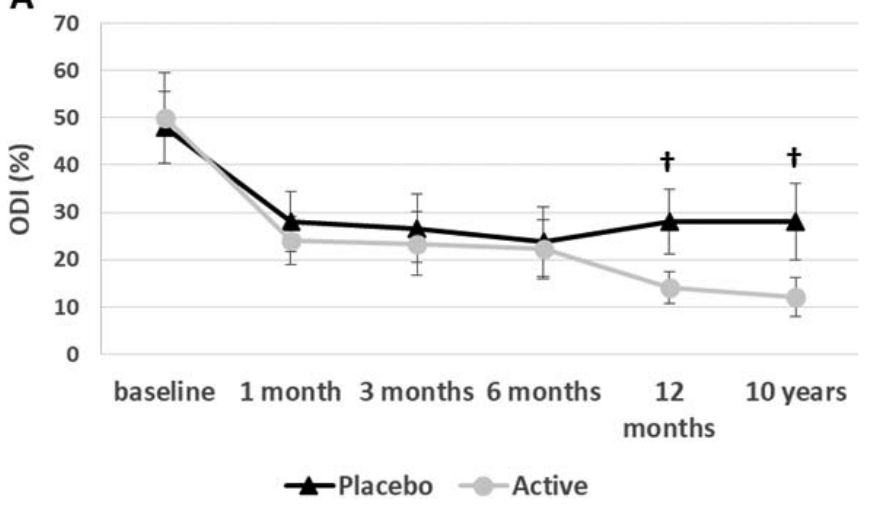

B

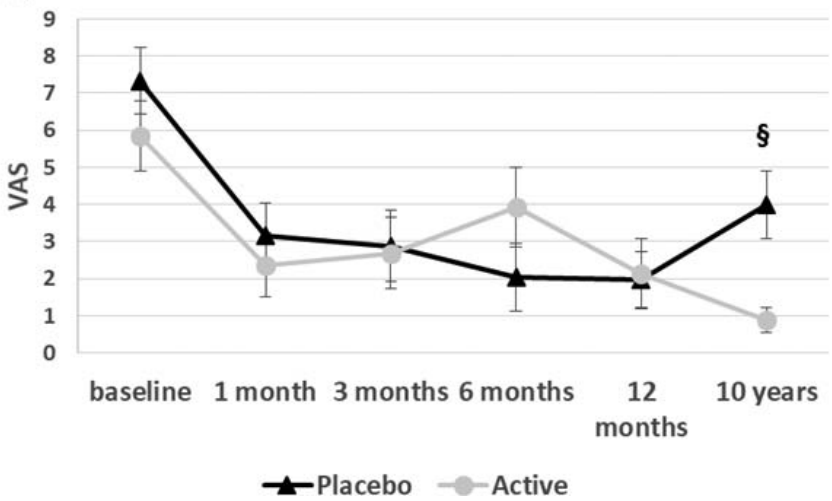

Figure 5. Quality of life measured by ODI and VAS scores. Graph showing mean ODI values (A) and mean VAS values (B). Data are reported as mean \pm SE; $P$ values refer to a comparison between groups at each follow-up visit $(\dagger P<.05, \S P<.01)$.

ating whether CCEF improves outcome of patients following LSF.

In the current study, no negative side effects were observed during and after the CCEF stimulation. At 12 months, a significant reduction in the ODI score was measured in the active versus the placebo group $(P<.05)$. In agreement with these results, we observed a significantly higher percentage of successful treatment at 12 months in the active group. Our results demonstrate that 3 months of CCEF treatment is effective in reducing disability.

In the active group, a statistically significant improvement in SF-36 score compared with baseline was recorded already 1 month from surgery; we also observed a significantly higher percentage of successful treatment at 6 and 12 months in the active group. Moreover, focusing the analysis on the patients who completed the SF-36 questionnaire at each follow-up, statistically significant differences between groups were measured at 6 and 12 months. Our findings strongly suggest that CCEF stimulation is able to increase the QoL in patients immediately after surgery, leading to a higher percentage of successful treatments at 6 and 12 months. CCEF stimulation proved to be effective in the above-mentioned clinical outcomes regardless the spinal disorder treated. Ten years after surgery, a subset of patients were re-evaluated: ODI and VAS scores showed a statistically significant improvement in the active compared with the placebo group.

The main limitation of this study is the small number of patients enrolled, due to strict inclusion criteria allowing only 2 intervertebral disc spaces undergoing fusion. Another limitation is the small number of patients with 10 years' follow-up; however, the complexity of recalling patients after so many years postsurgery has to be taken into consideration.

A recent call for action from the low back pain working group highlighted that chronic pain, leading to rest and medication, is linked with worsening disability, whereas active strategies such as exercise are associated with reduced disability and less reliance on formal health care. ${ }^{26}$ In this view, CCEF treatment after spine surgery leads to pain relief and better QoL, allowing the patient to return to previous activities and to an overall healthier life style, leading to a significant improvement in the medium and long-term outcomes. Our results suggest that CCEF stimulation should be used in clinical practice as an adjunct to spinal fusion in the treatment of spine diseases, for increasing overall QoL after surgery, thus improving patients' functional recovery.

\section{REFERENCES}

1. Mannion AF, Brox JI, Fairbank JCT. Comparison of spinal fusion and nonoperative treatment in patients with chronic low back pain: long-term follow-up of three randomized controlled trials. Spine J. 2013;13(11):1438-1448. doi:10. 1016/j.spinee.2013.06.101

2. Bydon M, De la Garza-Ramos R, Macki M, Baker A, Gokaslan AK, Bydon A. Lumbar fusion versus nonoperative management for treatment of discogenic low back pain: a systematic review and meta-analysis of randomized controlled trials. J Spinal Disord Tech. 2014;27(5):297-304. doi:10.1097/ BSD.0000000000000072

3. Gibson JNA, Waddell G. Surgery for degenerative lumbar spondylosis: updated Cochrane Review. Spine. 2005;30(20): 2312-2320.

4. Massari L, Benazzo F, Falez F, et al. Biophysical stimulation of bone and cartilage: state of the art and future 
perspectives. Int Orthop. 2019;43(3):539-551. doi:10.1007/ s00264-018-4274-3

5. Gan JC, Glazer PA. Electrical stimulation therapies for spinal fusions: current concepts. Eur Spine J. 2006;15(9):13011311. doi:10.1007/s00586-006-0087-y

6. Clark CC, Wang W, Brighton CT. Up-regulation of expression of selected genes in human bone cells with specific capacitively coupled electric fields: electrical stimulation of human osteoblasts. J Orthop Res. 2014;32(7):894-903. doi:10. 1002/jor. 22595

7. Brighton CT, Luessenhop CP, Pollack SR, Steinberg DR, Petrik ME, Kaplan FS. Treatment of castration-induced osteoporosis by a capacitively coupled electrical signal in rat vertebrae. J Bone Joint Surg Am. 1989;71(2):228-236.

8. Goodwin CB, Brighton CT, Guyer RD, Johnson JR, Light KI, Yuan HA. A double-blind study of capacitively coupled electrical stimulation as an adjunct to lumbar spinal fusions. Spine. 1999;24(13):1349-1356; discussion 1357.

9. Rossini M, Viapiana O, Gatti D, de Terlizzi F, Adami S. Capacitively coupled electric field for pain relief in patients with vertebral fractures and chronic pain. Clin Orthop Relat Res. 2010;468(3):735-740. doi:10.1007/s11999-009-1088-z

10. Piazzolla A, Solarino G, Bizzoca D, et al. Capacitive coupling electric fields in the treatment of vertebral compression fractures. J Biol Regul Homeost Agents. 2015;29(3):637-646.

11. Sansone V, McCleery J, Bonora C. Post-partum lowback pain of an uncommon origin: a case report. $J$ Back Musculoskelet Rehabil. 2013;26(4):475-477. doi:10.3233/BMR130394

12. Hawker GA, Mian S, Kendzerska T, French M. Measures of adult pain: Visual Analog Scale for Pain (VAS Pain), Numeric Rating Scale for Pain (NRS Pain), McGill Pain Questionnaire (MPQ), Short-Form McGill Pain Questionnaire (SF-MPQ), Chronic Pain Grade Scale (CPGS), Short Form-36 Bodily Pain Scale (SF-36 BPS), and Measure of Intermittent and Constant Osteoarthritis Pain (ICOAP). Arthritis Care Res. 2011;63(S11):S240-S252. doi:10.1002/acr.20543

13. Fairbank JC. The use of revised Oswestry Disability Questionnaire. Spine. 2000;25(21):2846-2847.

14. Mannion AF, Junge A, Fairbank JCT, Dvorak J, Grob D. Development of a German version of the Oswestry Disability Index. Part 1: cross-cultural adaptation, reliability, and validity. Eur Spine J. 2006;15(1):55-65. doi:10.1007/s00586004-0815-0

15. Cadossi M, Chiarello E, Savarino L, et al. A comparison of hemiarthroplasty with a novel polycarbonate-urethane acetabular component for displaced intracapsular fractures of the femoral neck: a randomised controlled trial in elderly patients. Bone Jt J. 2013;95-B(5):609-615. doi:10.1302/0301620X.95B5.31083

16. Cadossi M, Buda RE, Ramponi L, Sambri A, Natali S, Giannini S. Bone marrow-derived cells and biophysical stimulation for talar osteochondral lesions: a randomized controlled study. Foot Ankle Int. 2014;35(10):981-987. doi:10. $1177 / 1071100714539660$

17. Weinstein JN, Lurie JD, Tosteson TD, et al. Surgical compared with nonoperative treatment for lumbar degenerative spondylolisthesis: four-year results in the Spine Patient Outcomes Research Trial (SPORT) randomized and observational cohorts. J Bone Jt Surg-Am Vol. 2009;91(6):1295-1304. doi:10. 2106/JBJS.H.00913

18. Weinstein JN, Lurie JD, Olson PR, Bronner KK, Fisher ES. United States' trends and regional variations in lumbar spine surgery: 1992-2003: Spine. 2006;31(23):2707-2714. doi:10. 1097/01.brs.0000248132.15231.fe

19. Zhou J, Wang J-Q, Ge B-F, et al. Different electromagnetic field waveforms have different effects on proliferation, differentiation and mineralization of osteoblasts in vitro: effects of electromagnetic fields on osteoblasts. Bioelectromagnetics. 2014;35(1):30-38. doi:10.1002/bem.21794

20. Simmons JW. Treatment of failed posterior lumbar interbody fusion (PLIF) of the spine with pulsing electromagnetic fields. Clin Orthop. 1985;(193):127-132.

21. Risso Neto MI, Zuiani GR, Cavali PTM, et al. Effect of pulsed electromagnetic field on the consolidation of posterolateral arthrodesis in the lumbosacral spine: a prospective, double-blind, randomized study. Coluna/Columna. 2017;16(3):206-212. doi:10.1590/s1808-185120171603173661

22. Marks RA. Spine fusion for discogenic low back pain: outcomes in patients treated with or without pulsed electromagnetic field stimulation. Adv Ther. 2000;17(2):57-67.

23. Linovitz RJ, Pathria M, Bernhardt M, et al. Combined magnetic fields accelerate and increase spine fusion: a doubleblind, randomized, placebo controlled study. Spine. 2002;27(13):1383-1389; discussion 1389.

24. Mooney V. A randomized double-blind prospective study of the efficacy of pulsed electromagnetic fields for interbody lumbar fusions. Spine. 1990;15(7):708-712.

25. Dhall SS, Choudhri TF, Eck JC, et al. Guideline update for the performance of fusion procedures for degenerative disease of the lumbar spine. Part 5: correlation between radiographic outcome and function. J Neurosurg Spine. 2014;21(1):31-36. doi:10.3171/2014.4.SPINE14268

26. Buchbinder R, van Tulder M, Öberg B, et al. Low back pain: a call for action. Lancet. 2018;391(10137):2384-2388. doi:10.1016/S0140-6736(18)30488-4

Disclosures and COI: L. Massari has received consultant honoraria from IGEA SpA. Institutions 1, 2, and 4 have received a grant from IGEA SpA. S. Setti and S. Salati are employees of IGEA SpA. The other authors received no funding for this study and report no conflicts of interest.

Corresponding Author: Leo Massari, MD, University of Ferrara, Via Aldo Moro 8, 44124, Ferrara, Italy. Phone: (+39) 0532-236573; Fax: (+39) 0532-209250; Email: msl@unife.it.

Published 22 January 2021

This manuscript is generously published free of charge by ISASS, the International Society for the Advancement of Spine Surgery. Copyright (C) 2020 ISASS. To see more or order reprints or permissions, see http://ijssurgery.com. 